Pacific Journal of Mathematics

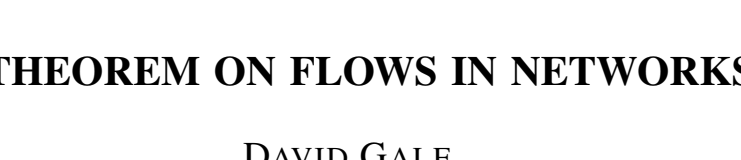




\title{
A THEOREM ON FLOWS IN NETWORKS
}

\author{
DAVID GALE
}

1. Introduction. The theorem to be proved in this note is a generalization of a well-known combinatorial theorem of P. Hall, [4].

Hall's Theorem. Let $S_{1}, S_{2}, \cdots, S_{n}$ be subsets of a set $X$. Then a necessary and sufficient condition that there exist distinct elements $x_{1}, \cdots, x_{n}$, such that $x_{i} \in S_{i}$ is that the union of every $k$ sets from among the $S_{i}$ contain at least $k$ elements.

The result has a simple interpretation in terms of transportation networks. A certain article is produced at a set $X$ of origins, and is demanded at $n$ destinations $y_{1}, \cdots, y_{n}$. Certain of the origins $x$ are " connected" to certain of the destinations $y$ making it possible to ship one article from $x$ to $y$.

Problem. Under what conditions is it possible to ship articles to all the destinations $y$ ?

An obvious reinterpretation of Hall's theorem shows that this is possible if and only if every $k$ of the destinations are connected to at least $k$ origins.

We shall now give a verbal statement of the generalization to be proved. A more formal statement will be given in the next section.

Let $N$ be an arbitrary network or graph. To each node $x$ of $N$ corresponds a real number $d(x)$, where $|d(x)|$ is to be thought of as the demand for or the supply of some good at $x$ according as $d(x)$ is positive or negative. To each edge $(x, y)$ corresponds a nonnegative real number $c(x, y)$, the capacity of this edge, which assigns an upper bound to the possible flow from $x$ to $y$.

The demands $d(x)$ are called feasible if there exists a flow in the network such that the flow along each edge is no greater than its capacity, and the net flow into (out of) each node is at least (at most) equal to the demand (supply) at that node.

An obviously necessary condition for the demands $d(x)$ to be feasible is the following.

For every collection $S$ of nodes the sum of the demands at the nodes

Received September 24, 1956. The results of this paper were discovered while the author was working as a consultant for the RAND Corporation. A later revision was partially supported by an O.N.R. contract. 
of $S$ must not exceed the sum of the capacities of the edges leading into $S$.

If this condition were not satisfied it would clearly be impossible to satisfy the aggregate demand of the subset $S$. The principal theorem of this paper shows that conversely, if the above condition is satisfied, then the demands $d(x)$ are feasible.

Hall's theorem drops out as a special case of this result if one applies it to the particular network described in the paragraph above and makes use of the known fact (see [1]) that transportation problems of this type with integral constraints have integral solutions. However, the simple inductive argument which works in [4] does not seem to generalize to yield a proof of our theorem. Our approach is in fact quite different and is based on the "minimum cut" theorem of Ford and Fulkerson, [2], [1].

In the next section we give a formal statement of the problem and prove the principal theorem. The final section is devoted to the treatment of a special case for which the "feasibility criterion" yields a very simple method for computing solutions.

2. The principal theorem. We proceed to define in a more formal manner the objects to be discussed.

Definitions. A network $[N, c]$ consists of a finite set of nodes $N$ and a capacity function $c$ on $N \times N$ where $c(x, y)$ is a nonnegative real number or plus infinity.

A flow $f$ on $[N, c]$ is a function $f$ on $N \times N$ such that

$$
\begin{aligned}
& f(x, y)+f(y, x)=0, \\
& f(x, y) \leqq c(x, y) \quad \text { for all } x, y \in N .
\end{aligned}
$$

A demand $d$ on $[N, c]$ is simply a real valued function on $N$.

Note that we do not require the function $c$ to be symmetric, thus the maximum allowable flow from $x$ to $y$ need not be the same as that from $y$ to $x$. Condition (1) above corresponds to the usual convention that the net flow from $x$ to $y$ is the negative of the net flow from $y$ to $x$.

We shall save writing many summation symbols in what follows by adopting the following convenient notation.

Notation. If $S$ is a subset of $N$ and $d$ a function on $N$, we write

$$
d(S)=\sum_{x \in S} d(x)
$$


If $S$ and $T$ are subsets of $N$ and $f$ a function on $N \times N$ we write

$$
f(S, T)=\sum_{x \in S, y \in T} f(x, y) .
$$

From these definitions it follows at once that if $U$ and $V$ are disjoint subsets of $N$ then

$$
\begin{gathered}
d(U \cup V)=d(U)+d(V) \\
f(S, U \cup V)=f(S, U)+f(S, V) .
\end{gathered}
$$

In particular, denoting the complement of $S$ by $S^{\prime}$ we have,

$$
f(N, T)=f(S, T)+f\left(S^{\prime}, T\right) \quad \text { for all } S \subset N .
$$

In this notation (1) and (2) are clearly equivalent to

$$
f(A, A)=0 \text {; }
$$

and

$$
f(A, B) \leqq c(A, B) \quad \text { for all } A, B \subset N .
$$

The above notation is natural to our problem, for if $d$ is a demand function then $d(S)$ is simply the aggregate demand of the set $S$, and if $f$ is a flow then $f(S, T)$ represents the net flow from $S$ into $T$.

Definition. A demand $d$ is called feasible if there exists a flow $f$ such that

$$
f(N, x) \geqq d(x) \quad \text { for } x \in N .
$$

This condition states that the flow into each node must be at least equal to the demand at that node. However (1) and (4) together imply

$$
f(x, N) \leqq-d(x)
$$

so that we are also requiring the flow out of each node to be at most equal to the supply at that node (recalling that a negative demand represents a supply).

Finally we note that from (3) it follows that (4) is equivalent to

$$
f(N, S) \geqq d(S) \quad \text { for all } S \subset N .
$$

We can now give a simple statement of our main result.

Feasibility Theorem. The demand $d$ is feasible if and only if for every subset $S \subset N$

$$
d\left(S^{\prime}\right) \leqq c\left(S, S^{\prime}\right)
$$


Proof. The necessity of (5) is obvious, for if $d$ is feasible then there is a flow $f$ such that

$$
d\left(S^{\prime}\right) \leqq f\left(N, S^{\prime}\right)=f\left(S, S^{\prime}\right)+f\left(S^{\prime}, S^{\prime}\right)=f\left(S, S^{\prime}\right) \leqq c\left(S, S^{\prime}\right)
$$

The proof of sufficiency depends on the "minimum cut theorem" of Ford and Fulkerson, which we shall now state and prove in our own formulation. While our proof is little more than a translation of the above authors' second proof [3] into our notation, we record it here, nevertheless, both for the sake of completeness and because it is substantially shorter than any proof published heretofore.

Definition. Let $[N, c]$ be a network and let $s$ and $s^{\prime}$ be two distinguished nodes ( $s=$ source, $s^{\prime}=\operatorname{sink}$ ). A flow from $s$ to $s^{\prime}$ is a flow such that

$$
f(N, x)=0 \quad \text { for } x \neq s, x \neq s^{\prime} .
$$

Let $F$ denote the set of all flows from $s$ to $s^{\prime}$.

A cut $\left(S, S^{\prime}\right)$ of $N$ with respect to $s$ and $s^{\prime}$ is a partition of $N$ into sets $S$ and $S^{\prime \prime}$ such that $s \in S, s^{\prime} \in S^{\prime \prime}$.

Let $Q$ denote the set of all such cuts.

Minimum Cut Theorem. For any network $[N, c]$

$$
\max _{F} f(s, N)=\min _{Q} c\left(S, S^{\prime}\right),
$$

Proof. First note that for any flow $f \in F$ and cut $\left(S, S^{\prime}\right) \in Q$ we have

$$
\begin{aligned}
f(s, N) & =f(s, N)+\sum_{x \in S-s} f(x, N)=f(s, N)+f(S-s, N) \\
& =f(S, N)=f(S, S)+f\left(S, S^{\prime}\right)=f\left(S, S^{\prime}\right) \leqq c\left(S, S^{\prime}\right) .
\end{aligned}
$$

Hence, it remains only to show that equality is attained in (7) for some flow and cut.

Let $\bar{f} \in F$ be a flow such that $\bar{f}(s, N)$ is a maximum. Let $S$ consist of $s$ and all nodes $x$ such that there exists a chain $\sigma=\left(x_{0}, x_{1}, \cdots, x_{n}\right)$ of distinct nodes with $x_{0}=s, x_{n}=x$ and $\left.c\left(x_{i-1}, x_{i}\right)-\overline{f(} x_{i-1}, x_{i}\right)>0, i=1$, $\cdots, n$. Now $s^{\prime}$ is not in $S$, for, if it were, there would be a chain $\sigma$ as above with $x=s^{\prime}$. But then letting

$$
\mu=\min \left[c\left(x_{i-1}, x_{i}\right)-\bar{f}\left(x_{i-1}, x_{i}\right)\right],
$$

one could superimpose a flow of $\mu$ along the chain $\sigma$ on top of the flow $\bar{f}$, contradicting the maximality of $\bar{f}$. 
The above argument shows that $\left(S, S^{\prime}\right)$ is a cut, and we conclude the proof by observing that $\overline{f(s, N)}=c\left(S, S^{\prime}\right)$, for if not, then from (7), $\bar{f}\left(S, S^{\prime}\right)<c\left(S, S^{\prime}\right)$, hence for some $x \in S$ and $y \in S^{\prime}$ we would have $c(x, y)$ $-\bar{f}(x, y)>0$, but since $x \in S$ there is a chain $\sigma=\left(s, x_{1}, \cdots, x\right)$ which could be extended to a chain $\sigma^{\prime}=\left(s, x_{1}, \cdots, x, y\right)$, contrary to the fact that $y \in S^{\prime}$. This completes the proof.

Proof of feasibility theorem. Consider a new network $[\bar{N}, \bar{c}]$ where $\bar{N}$ consists of $N$ plus two additional nodes $s$ and $s^{\prime}$. Let $U \subset N$ be all nodes $x$ such that $d(x) \leqq 0$. Then $\bar{c}$ is defined by the rules

$$
\begin{array}{ll}
\bar{c}(x, y)=c(x, y) & \text { for } x, y \in N, \\
\bar{c}(s, x)=-d(x) & \text { for } x \in U, \\
\bar{c}\left(x, s^{\prime}\right)=d(x) & \text { for } x \in U^{\prime}, \\
\bar{c}(x, y)=0 & \text { otherwise. }
\end{array}
$$

We now assert that the cut $\left(\bar{N}-s^{\prime}, s^{\prime}\right)$ is a minimal cut of $[\bar{N}, \bar{c}]$, for let $\bar{S}$, and $\overline{S^{\prime}}$ be any cut of $[\bar{N}, \bar{c}]$ and let $S=\bar{S}-s, S^{\prime}=\overline{S^{\prime}}-s^{\prime}$. From the definition above we have

$$
\begin{aligned}
& \bar{c}\left(\bar{S}, \overline{S^{\prime}}\right)=c\left(S, S^{\prime}\right)+\bar{c}\left(s, S^{\prime}\right)+\bar{c}\left(S, s^{\prime}\right) \\
&=c\left(S, S^{\prime}\right)-d\left(S^{\prime} \cap U\right)+d\left(S \cap U^{\prime}\right), \\
& \bar{c}\left(\bar{N}-s^{\prime}, s^{\prime}\right)=d\left(U^{\prime}\right)=d\left(S^{\prime} \cap U^{\prime}\right)+d\left(S \cap U^{\prime}\right) ;
\end{aligned}
$$

and subtracting we get

$$
\begin{gathered}
\bar{c}\left(\bar{N}-s^{\prime}, s^{\prime}\right)-\bar{c}\left(\bar{S}, \overline{S^{\prime}}\right)=d\left(S^{\prime} \cap U^{\prime}\right)+d\left(S^{\prime} \cap U\right)-c\left(S, S^{\prime}\right) \\
=d\left(S^{\prime}\right)-c\left(S, S^{\prime}\right) \leqq 0,
\end{gathered}
$$

the last inequality being the hypothesis (5), and the assertion is proved.

Now, from the Minimum Cut Theorem, there is a flow $\bar{f}$ from $s$ to $s^{\prime}$ on $[\bar{N}, \bar{c}]$ such that

$$
\bar{f}\left(\bar{N}-s^{\prime}, s^{\prime}\right)=\bar{c}\left(\bar{N}-s^{\prime}, s^{\prime}\right)=d\left(U^{\prime}\right),
$$

hence

$$
\bar{f}\left(x, s^{\prime}\right)=d(x)
$$
for all $x \in U^{\prime}$.

Let $f$ be $\bar{f}$ restricted to $N \times N$. Then $f$ is clearly a flow and it remains to show that $f$ satisfies (4). If $x \in U^{\prime}$ then

$$
0=\bar{f}(x, \bar{N})=f(x, N)+\bar{f}\left(x, s^{\prime}\right)=f(x, N)+d(x),
$$


hence

$$
f(N, x)=d(x)
$$

If $x \in U$ then

$$
0=\bar{f}(\bar{N}, x)=f(N, x)+\bar{f}(s, x) \leqq f(N, x)+\bar{c}(s, x)=f(N, x)-d(x),
$$

so

$$
f(N, x) \geqq d(x),
$$

and (9) and (10) together show that $f$ satisfies (4), completing the proof.

REMARK. We wish to call attention to the following important fact. We have at no point in what has been said thus far made use of the assumption that the functions $d, c$ and $f$ were real valued. In fact, all definitions and proofs go through verbatim if the real numbers are replaced by any ordered Abelian group, in particular, the group of integers. One useful consequence of this remark is the fact that if a network with integer valued demand and capacity functions admits a feasible flow then this flow may also be chosen to be integer valued. We shall make use of this fact in the next section.

There is a second formulation of the Feasibility Theorem which is sometimes convenient. In the network $[N, c]$ let $U$ be as above the set of nodes $x$ such that $d(x) \leqq 0$.

Theorem. The demand $d$ is feasible if and only if for every set $Y \subset U^{\prime}$ there exists a flow $f_{Y}$ such that

$$
\begin{array}{cc}
f_{Y}(N, x) \geqq d(x) & \text { for } x \in U \\
f_{Y}(N, Y) \geqq d(Y) . &
\end{array}
$$

Proof. The necessity is obvious. To prove sufficiency we show that (11) and (12) imply (5).

Let $\left(S, S^{\prime}\right)$ be a partition of $N$ and let $X=U \cap S, X^{\prime}=U \cap S^{\prime}$, $Y=U^{\prime} \cap S, Y^{\prime}=U^{\prime} \cap S^{\prime}$. Then from (11) there exists $f_{Y^{\prime}}$ such that

$$
d\left(X^{\prime}\right) \leqq f_{Y^{\prime}}\left(N, X^{\prime}\right)=f_{Y^{\prime}}\left(X \cup Y, X^{\prime}\right)+f_{Y^{\prime}}\left(Y^{\prime}, X^{\prime}\right),
$$

and from (12),

$$
d\left(Y^{\prime}\right) \leqq f_{Y^{\prime}}\left(N, Y^{\prime}\right)=f_{Y^{\prime}}\left(X \cup Y, Y^{\prime}\right)+f_{Y^{\prime}}\left(X^{\prime}, Y^{\prime}\right) .
$$

Adding these inequalities we get 


$$
\begin{aligned}
d\left(S^{\prime}\right) & =d\left(X^{\prime}\right)+d\left(Y^{\prime}\right)=f_{Y^{\prime}}\left(X \cup Y, X^{\prime}\right)+f_{Y^{\prime}}\left(X \cup Y, Y^{\prime}\right) \\
& =f_{Y^{\prime}}\left(X \cup Y, X^{\prime} \cup Y^{\prime}\right)=f\left(S, S^{\prime}\right) \leqq c\left(S, S^{\prime}\right),
\end{aligned}
$$

which is exactly (5).

3. An example. As an illustration of the feasibility theorem, consider the following problem.

(I). Let $a_{1}, \cdots, a_{m}$ and $b_{1}, \cdots, b_{n}$ be two sets of positive integers. Under what conditions can one find integers $\alpha_{i j}=0$ or 1 , such that

$$
\sum_{i=1}^{m} \alpha_{i \jmath} \geqq b_{j}
$$

and

$$
\sum_{j=1}^{n} \alpha_{i j} \leqq a_{i}
$$

for all $i$ and $j$ ?

As a concrete illustration, suppose $n$ families are going on a picnic in $m$ busses, where the $j$ th family has $b_{j}$ members and the $i$ th bus has $a_{i}$ seats. When is it possible to seat all passengers in such a way that no two members of the same family are in the same bus?

In the case $\sum a_{i}=\sum b_{i}$ the problem becomes that of filling an $m \times n$ matrix $M$ with zeros and ones so that the rows and columns shall have prescribed sums.

The feasibility theorem gives a simple necessary and sufficient condition for the problem to have a solution. In order to state if we need the following.

DEFINITION. Let $\left\{a_{i}\right\}$ be a nonincreasing sequence of nonnegative integers $a_{1}, a_{2}, \cdots$, such that all but a finite number of the $a_{i}$ are zero. Let

$$
S_{j}=\left\{a_{i} \mid a_{i} \geqq j\right\}
$$

where $j$ is a positive integer and let $s_{j}$ be the number of elements in $S_{j}$. The sequence of numbers $\left\{s_{j}\right\}$ clearly satisfies the same conditions as the sequence $\left\{a_{i}\right\}$; it is called the dual sequence of the sequence $\left\{a_{i}\right\}$ and is denoted by $\left\{a_{i}\right\}^{*}$.

It is clear that $\left\{a_{i}\right\}^{*}$ determines $\left\{a_{i}\right\}$ since the integer $a_{i}$ occurs exactly $s_{a_{i}}-s_{a_{i}+1}$ times in $\left\{a_{i}\right\}$. Actually the correspondence between $\left\{a_{i}\right\}$ and $\left\{a_{i}\right\}^{*}$ is completely dual in the following sense.

THEOREM.

$$
\left\{a_{i}\right\}^{* *}=\left\{a_{i}\right\} .
$$

This result will not be needed in the sequel and its proof is left as 
an exercise. However, its validity can be made quite obvious by means of a simple pictorial representation.

Let each number $a_{i}$ be represented by a row of dots, and write these rows in a vertical array so that $a_{i+1}$ lies under $a_{i}$, thus:

$$
\begin{aligned}
& a_{1} \cdots \\
& a_{2} \cdots \\
& a_{3} \cdots \\
& a_{4} \cdots \\
& a_{5} \cdot
\end{aligned}
$$

It is then clear that the dual number $s_{j}$ is simply the number of dots in the $j$ th column of the array.

We can now give the criterion for the feasibility of Problem I. Henceforth for convenience we shall assume the numbers $a_{i}$ and $b_{j}$ are indexed in decreasing order, and shall define $a_{i}=0$ for $i>m, b_{j}=0$ for $j>n$.

Theorem. Let $\left\{s_{j}\right\}=\left\{a_{i}\right\}^{*}$. Then Problem 1 is feasible if and only if

$$
\sum_{j=1}^{k} b_{j} \leqq \sum_{j=1}^{k} s_{j}, \quad \text { for all integers } k \text {. }
$$

Proof. We may interpret (I) as a flow problem. Let $N$ be a network consisting of $m+n$ nodes $x_{1}, \cdots, x_{m}$ and $y_{1}, \cdots, y_{n}$, and let $c\left(x_{i}, y_{i}\right)$ $=1$ for all $i$ and $j, c=0$ otherwise. Let $d\left(x_{i}\right)=-a_{i}$ and $d\left(y_{j}\right)=b_{j}$. One easily verifies that the feasibility of (I) is equivalent to the feasibility of the demand $d$.

We shall show that $d$ is feasible by applying the second theorem of the previous section. Let $Y$ be a subset of $k$ nodes $y_{j}$, say $Y=\left\{y_{j_{1}}\right.$, $\left.\cdots, y_{j_{k}}\right\}$. We now compute the maximum possible flow into $Y$. Because all capacities are unity this maximal flow $f_{Y}$ is achieved by shipping as much as possible from each node $x_{i}$ into the set $Y$. Thus, the flow from $x_{i}$ to $Y$ is $\min \left[a_{i}, k\right]$ and the total flow into $Y$ is

$$
f_{Y}(N, Y)=\sum_{i=1}^{m} \min \left[a_{i}, k\right] \text {. }
$$

We now assert

$$
\sum_{i=1}^{m} \min \left[a_{i}, k\right]=\sum_{j=1}^{k} s_{j}
$$


which is proved by induction on $k$. It is clear from the definition that

$$
\sum_{i=1}^{m} \min \left[a_{i}, 1\right]=m=s_{1} .
$$

Now

$$
\min \left[a_{i}, k+1\right]= \begin{cases}\min \left[a_{i}, k\right] & \text { for } a_{i} \leqq k \\ \min \left[a_{i}, k\right]+1 & \text { for } a_{i} \geqq k+1, \text { or } a_{i} \in S_{k+1},\end{cases}
$$

hence,

$$
\sum_{i=1}^{m} \min \left[a_{i}, k+1\right]=\sum_{i=1}^{m} \min \left[a_{i}, k\right]+s_{k+1},
$$

and (13) follows from the induction hypothesis.

The second feasibility theorem now states that the problem is feasible if and only if

$$
\sum_{r=1}^{k} b_{j_{r}} \leqq \sum_{j=1}^{k} s_{j},
$$

and since the $b_{j}$ are indexed in decreasing order, the conclusion of the theorem follows.

It is interesting that for this particular problem there is a simple " $n$-step" method for actually filling out the matrix of $\alpha_{i j}^{\prime}$ 's. Such procedures are sufficiently rare in programming theory so that it seems worth while to present it here.

The procedure is the following: If the problem is feasible then $b_{1} \leqq s_{1}$ and hence $a_{1}, \cdots, a_{b_{1}} \geqq 1$ (recall that the $a_{i}$ 's are indexed in descending order). Let $\alpha_{i 1}=1$ for $i \leqq b_{1}, \alpha_{i 1}=0$ for $i>b_{1}$. Now consider the new problem, $(\mathrm{I})^{\prime}$, with the matrix $M^{\prime}$ having $m$ rows and $n-1$ columns, $j=2, \cdots, n$, with $a_{i}^{\prime}=a_{i}-\alpha_{i 1}$ and $b_{j}^{\prime}=b_{j}$. We assert that (I) is again feasible so that by repeating the process we will eventually fill out the whole matrix.

To show that $(\mathrm{I})^{\prime}$ is feasible we must prove, for any $k$,

$$
\sum_{j=2}^{k+1} b_{j} \leqq \sum_{j=1}^{k} s_{j}^{\prime}=\sum_{i=1}^{m} \min \left[s_{i}^{\prime}, k\right],
$$

where $\left\{s_{i}^{\prime}\right\}$ is the dual sequence to $\left\{\alpha_{i}^{\prime}\right\}$. The expression on the right can be rewritten

$$
\sum_{i=1}^{m} \min \left[a_{i}^{\prime}, k\right]=\sum_{i=1}^{b_{1}} \min \left[a_{i}-1, k\right]+\sum_{i=b_{1}+1}^{m} \min \left[a_{i}, k\right] .
$$

We must now consider two cases.

Case 1. $s_{k+1} \geqq b_{1}$. Then $a_{i}-1 \geqq k$ for $i \leqq b_{1}$ and hence $\min \left[a_{i}-1, k\right]$ 
$=k=\min \left[a_{i}, k\right]$, so that we get

$$
\sum_{j=1}^{k} s_{j}^{\prime}=\sum_{i=1}^{m} \min \left[a_{i}^{\prime}, k\right]=\sum_{i=1}^{m} \min \left[a_{i}, k\right]=\sum_{j=1}^{k} s_{j} \geqq \sum_{j=1}^{k} b_{j} \geqq \sum_{j=2}^{k+1} b_{j} .
$$

Case 2. $s_{k+1}<b_{1}$. Then for $i \leqq s_{k+1}, a_{i} \geqq k+1$ so $a_{i}-1 \geqq k$ and $\min \left[a_{i}-1, k\right]=k=\min \left[a_{1}, k\right]$. For $s_{k+1}<i \leqq b_{1}, a_{i} \leqq k$, so $\min \left[a_{i}-1, k\right]$ $=\min \left[a_{i}, k\right]-1$, hence,

$$
\sum_{i=1}^{m} \min \left[a_{i}^{\prime}, k\right]=\sum_{i=1}^{m} \min \left[a_{i}, k\right]-b_{1}+s_{k+1}=\sum_{j=1}^{k+1} s_{j}-b_{1} \geqq \sum_{i=2}^{k+1} b_{j},
$$

since

$$
\sum_{j=1}^{k+1} s_{j} \geqq \sum_{j=1}^{k+1} b_{j}
$$

by the feasibility condition. The proof is now complete.

In terms of the picnic problem, the $n$ families should be seated in $n$ stages according to the following simple rule: at each stage distribute the largest unseated family among those busses having the greatest number of vacant seats.

\section{REFERENCES}

1. G. B. Dantzig and D. R. Fulkerson, On the max-flow min-cut theorem of networks, Ann. of Math. Study No. 38, Contributions to linear inequalities and related topics, edited by H. W. Kuhn and A. W. Tucker, 215-221.

2. L. R. Ford, Jr., and D. R. Fulkerson, Maximal flow through a network, Canad. J. Math. 8 (1956), 399-404.

3. - A simple algorithm for finding maximal network flows aud an application to the Hitchcock problem, Canad. J. Math. 9 (1957), 210-218.

4. P. Hall. On Representatives of Subsets, J. London Math. Soc., 10 (1935), 26-30.

THE RAND CORPORATION AND

BROWN UNIVERSITY 


\section{PACIFIC JOURNAL OF MATHEMATICS}

\section{EDITORS}

H. L. ROYDEN

Stanford University

Stanford, California

R. A. Beaumont

University of Washington

Seattle 5, Washington

\section{A. L. Whiteman}

University of Southern California

Los Angeles 7, California

E. G. Straus

University of California

Los Angeles 24, California

\section{ASSOCIATE EDITORS}
E. F. BECKENBACH
C. E. BURGESS
M. HALL
E. HEWITT

\author{
A. HORN \\ V. GANAPATHY IYER \\ R. D. JAMES \\ M. S. KNEBELMAN
}

L. NACHBIN

I. NIVEN

G. SZEKERES

T. G. OSTROM

M. M. SCHIFFER
F. WOLF

K. YOSIDA

\section{SUPPORTING INSTITUTIONS}

\author{
UNIVERSITY OF BRITISH COLUMBIA \\ CALIFORNIA INSTITUTE OF TECHNOLOGY \\ UNIVERSITY OF CALIFORNIA \\ MONTANA STATE UNIVERSITY \\ UNIVERSITY OF NEVADA \\ OREGON STATE COLLEGE \\ UNIVERSITY OF OREGON \\ UNIVERSITY OF SOUTHERN CALIFORNIA
}

\author{
STANFORD UNIVERSITY \\ UNIVERSITY OF UTAH \\ WASHINGTON STATE COLLEGE \\ UNIVERSITY OF WASHINGTON \\ AMERICAN MATHEMATICAL SOCIETY \\ CALIFORNIA RESEARCH CORPORATION \\ HUGHES AIRCRAFT COMPANY \\ THE RAMO-WOOLDRIDGE CORPORATION
}

Mathematical papers intended for publication in the Pacific Journal of Mathematics should be typewritten (double spaced), and the author should keep a complete copy. Manuscripts may be sent to any of the editors. All other communications to the editors should be addressed to the managing editor, E. G. Straus at the University of California, Los Angeles 24, California.

50 reprints per author of each article are furnished free of charge; additional copies may be obtained at cost in multiples of 50 .

The Pacific Journal, of Mathematics is published quarterly, in March, June, September, and December. The price per volume (4 numbers) is $\$ 12.00$; single issues, $\$ 3.50$. Back numbers are available. Special price to individual faculty members of supporting institutions and to individual members of the American Mathematical Society: $\$ 4.00$ per volume; single issues, $\$ 1.25$.

Subscriptions, orders for back numbers, and changes of address should be sent to Pacific Journal of Mathematics, 2120 Oxford Street, Berkeley 4, California.

Printed at Kokusai Bunken Insatsusha (International Academic Printing Co., Ltd.), No. 10, 1-chome, Fujimi-cho, Chiyoda-ku, Tokyo, Japan.

PUBLISHED BY PACIFIC JOURNAL OF MATHEMATICS, A NON-PROFIT CORPORATION

The Supporting Institutions listed above contribute to the cost of publication of this Journal, but they are not owners or publishers and have no responsibility for its content or policies. 


\section{Pacific Journal of Mathematics}

\section{Vol. 7, No. 2 \\ February, 1957}

William F. Donoghue, Jr., The lattice of invariant subspaces of a completely continuous quasi-nilpotent transformation ................... 1031

Michael (Mihály) Fekete and J. L. Walsh, Asymptotic behavior of restricted extremal polynomials and of their zeros.................... 1037

Shaul Foguel, Biorthogonal systems in Banach spaces ............... 1065

David Gale, A theorem on flows in networks ................... 1073

Ioan M. James, On spaces with a multiplication .................. 1083

Richard Vincent Kadison and Isadore Manual Singer, Three test problems in operator theory .................................... 1101

Maurice Kennedy, A convergence theorem for a certain class of Markoff processes........................................ 1107

G. Kurepa, On a new reciprocity, distribution and duality law ........ 1125

Richard Kenneth Lashof, Lie algebras of locally compact groups ........ 1145

Calvin T. Long, Note on normal numbers .................... 1163

M. Mikolás, On certain sums generating the Dedekind sums and their reciprocity laws ..................................... 1167

Barrett O'Neill, Induced homology homomorphisms for set-valued maps......................................... 1179

Mary Ellen Rudin, A topological characterization of sets of real numbers........................................... 1185

M. Schiffer, The Fredholm eigen values of plane domains 1187

F. A. Valentine, A three point convexity property .........

Alexander Doniphan Wallace, The center of a compact lattice is totally

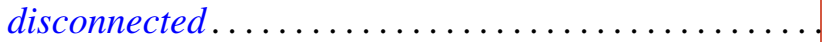

Alexander Doniphan Wallace, Two theorems on topological lattices.

G. T. Whyburn, Dimension and non-density preservation of mappings...

John Hunter Williamson, On the functional representation of certain algebraic systems ... 